\title{
ENGINES OF GROWTH AND PATHS OF DEVELOPMENT IN THE EUROZONE
}

Annamaria SIMONAZZı

The eurozone has entered a period of enduring stagnation, with its Southern European members marred in austerity and recession. At the global level, the specter of a "secular stagnation" has revived long-forgotten theories. Within this context, industry is back in fashion as an engine for growth, and re-industrialisation has become a strategic goal. After the liberal phase of the last decades, industrial economists seem to agree on the need for a "new" industrial policy, which is required to tackle both the structural disadvantages of the various countries and their regions, and the challenges of globalization and the knowledge economy.

While there is agreement on the premise, views differ widely on how to achieve it. In the mainstream approach the problem of development is mostly to achieve static efficiency: to better allocate resources by countering the market failures caused by monopolies, asymmetric information, and externalities. On the other hand, the network theory of development stresses the need for a multilevel analysis to capture the interactions between firms and institutions, and the interdependence of aggregate demand and the supply of products and capabilities. Government policy is called to coordinate the dispersed actions of firms, help them identify new opportunities for differentiation and up-grading, and contribute in developing the capabilities that are needed for the production of more complex products.

The first part of the paper briefly reviews the historical evolution of the network theory of development while the second part will investigate its implication for policies required to sustain growth and development in the Southern European members of the Eurozone

Annamaria Simonazzi - Università degli Studi di Roma “La Sapienza” I annamaria.simonazzi@uniroma1.it 